health, and had no tendency to fever, although the temperature was remarkably high for the month of June.

I have not seen a similar accident during my fifteen years' residence in France, but I presume they are not unfrequent here, or there would be no reason for the vulgar French ex. pression "Mauvaise comme une chenille." A. GILLANDER

7, Rue St. Claire, Passy, Paris

\section{The Glacial Period}

Prof. TYNDALI has several times called attention to a point in regard to the height of the snow-line, which seems to be steadily overlooked by those who spectulate on the causes of the great prevalence of snow during the glacial epoch. It is of course well known that the height of the snow-line at any place is determined mainly by two things, viz., the depth of annual snow-fall, and the temperature of the place. If the amount of snow falling over the whole earth is to be increased, the evapora. tion must also be increased. ("Ieat as a Mode of Motion," pp. 206-7. New York, I866.) This would also raise the tem. perature, but the snow-line might nevertheless descend. IVe have a case of exactly this kind in the Himalayas. On the warm southern side of these mountains the snow-line is, nevertheless, $3, \infty 00 \mathrm{ft}$. lower than on the northern side, where the temperature is very much colder. This is evidently due to a difference in the amount of annual precipitation. Assume that the sun was at one time much warmer than now, and that since then it has been steadily cooling; and I believe you have the key to the solution of the questions asked by J. H. Rohrs, as well as to such questions as the widespread occurrence of tropical vegeta. tion during the past ages.

Iowa City, U.S.

FRANK E. Nipher

\section{RECENT RESEARCHES ON THE LOCALISA-}

\section{TION OF THE CEREBRAL FUNCTIONS}

THE fifth part of Dr. Brown-Séquard's new "Archives of Scientific and Practical Medicine" contains an excellent report by Dr. Neftel, "on some of the recent researches in neuropathology" embracing a digest of several important modern methods, recently introduced, for the purpose of analysing the functions of the different parts of the cerebral hemispheres, together with a succinct account of the results arrived at by their employment. An abstract of this report forms the substance of the present notice.

The researches of Longet, Magendie, Matteucci, and others have led to the assumption by most physiologists, that the cerebral hemispheres, especially their cortical substance, are destitute of sensibility, being the seats of origin of higher mental phenomena only. The experiments from which these conclusions were arrived at, consisted in the irritation of the hemispheres in living animals by mechanical, chemical, and electrical means; and in none were they succeeded by muscular contractions. As if to put the question beyond a doubt, Flourens removed the entire hemispheres without disturbing the muscular mechanism.

But the tendency of modern observation is in a different direction; the new researches have been made inde. pendently by several investigators, with entirely different methods, nevertheless the results are the same, contrary to that of the earlier workers ; the evidence going to prove that the cortical substance of the cerebral hemispheres is in close relation with certain muscular groups, forming the "psychomotor centres" of Gudden.

Fritsch and Hitzig commenced these researches, the latter having observed that galvanic excitation of the hemispheres in the living man produced contraction of the eye-muscles. This aberrant result suggested further experiments. They irritated the cerebral hemispheres in a dog with an extremely weak current, and found that movements of certain groups of muscles followed the excitation of definite spots on the anterior convex portion of the brain, always upon the side opposite to that which was acted on; whilst the same excitation of portions of the hcmispheres situated more posteriorily, produced no effect. Thus they found the centre for the extensor and adductor muscles of the anterior extremity at the external end of the pre-frontal convolution; and somewhat be: hind it the centre for the flexor and rotating muscles of the same extremity. The irritation of these centres by metallic closing of a very weak galvanic current produces a single contraction, whilst the interrupted current produces tonic and gradually disappearing contractions of these muscles, followed by epileptiform movements. The anode has much more influence in producing these results than the cathode, so much so, that with a current of minimal intensity contractions can only be produced by the anode.

When Fritz and Hitzig removed in dogs the contre for the anterior extremity, this latter did not become entirely paralysed, the animal could use it, but imperfectly, and seemed quite unconscious of the condition of the limb, which could be placed into any position without attracting its attention.

Nothnagel employs a new method for the detcrmination of the functions of the brain. His observations are made mostly on rabbits. An incision is made in the scalp, the skull is perforated with a needle. Through the canal thus formed in the bone a very small drop of a con. centrated solution of chromic acid is injected by means of a hypodermic syringe with a very slender nozzle. The scalp wound is then united by suture, and the animal does not seem to be affected, except with regard to the functional derangement incidental to the lesion. Generally they survive the operation two or three weeks, and die from causes which Nothnagel cannot explain, no constitutional symptoms being developed. However, when the chromic acid is injected into the lateral cerebral ventricles death is the immediate result. On post-mortem examination, where the chromic acid was injected a minute circumscribed place appears, of a green colour, resistant and hard.

In methods employed previous to this, many causes acted to impair the value of the results arrived at ; there was considerable hremorrhage, refrigeration of the brain surface, and modification of the intra-cranial pressure, in addition to which the animal died very shortly. These are obviatcd by the new means just described; many fresh facts have therefore been brought to light. In one of his experiments Nothnagel made a chromic acid lesion on the surface of the cerebral cortex, which penetrated very slightly into its substance, in a spot corresponding exactly to the outer end of the post-frontal convolution. The animal appeared healthy, but it was found on careful observation that it had lost the muscular sense in the anterior extremity, on the opposite side to the cerebral lesion, it being possible to put, and retain for some time, the affected paw in strained positions. This condition passed off before death, which seems to indicate that the terminal station or the real centre for the muscular sense exists else:where, and that after a time other ways to it become developed.

Nothnagel found, further, a circumscribed locality in the cerebral cortex, the lesion of which produces a partial and transient hemiplegia of the opposite extremity. This spot is in front of that for the muscular sense, and deeper than it. In no other portions of the cerebral cortex, except those above mentioned, have the chromic acid lesions been followed by paralytic symptorns.

Gudden has introduced another method by which the function of the different parts of the cerebrum may be studied. He finds that newly-born animals, as rabbits, will undergo a very great amount of mutilation without interfering seriously with the nutritive functions, so that portions of the brain may be removed, and the animal will grow to full size, with no peculiarities excepting those resulting from the absence of the parts removed. The slight sensibility, rapid coagulation of the blood, and the 
quick growth, are all in favour of operations. The following are the results of his expcriments on the cerebral hemispheres:-_"Very convincing facts are obtained by removing the cerebral hemispheres in new-born animals, and allowing them to grow up. The result is idiotismus. There is also reason to locate the organic conditions of voluntary movements in the cortical substance of the brain, but there is no reason to accept the corfus striatum as a motor ganglion. The hemiplegion following the destruction of the nucleus lenticularis can be satisfactorily explained by the rupture of fibres passing through the internal capsule. But admitting the cerebral cortex as the organ for voluntary movements, there is no necessity to have another motor ganglion. Incleed, Gudden's experiments on new-born rabbits, by remoring portions of the hemispheres, have demonstrated that the organ of voluntary motion is located in the frontal part of the ccrebral cortex."

Dr. Ferrier, whose results are referred to in another column, is working in a similar ficld of observatinn, with the view of elucidating the relations between certain convolution centres, and definite sets of muscles at the periphery.

\section{FRENCH ASSOCIATION FOR THE ADVAN'CE MIENT OF SCIENCE}

THE sccond meeting of the French Association for the Advancement of Science was held at Lions from the 2 Ist to the 28th of August, under the Presidency of Prof. Quatrcfages. This Association bids fair to become as popular in France as the British Association in this country. The work done in the sections which I visited, those of Anthropology and Geology, was, to say the very least, as valuable as that done by our own sections. Among the papers brousht before the former, the ple istocene station of Solutré excited considerable interest, and was subsequen!ly visitcd by the section. The site has been used by man for habitation and buris.l, as late as the Merovingian times, in which it was a cemetery, and the strata are to a considerable extert remanié. The association of remains on that spot of varying age, Palrolithic, Neolithic, and Frar.kish, seerss to throw a doubt on the precise date of the human skeletons, buried at full length, and generally believed to be of the same age as the associated implements of reindecr, and bones of mammoth. Dr. Gosse also read a paper on the reindeer-cave of Veyriers, Switzerland, and exhibited carved implements of reindeer antler, usually called "batons de commandement," which are of the same form as the arrow-straighteners of the Eskimos. Here, as in the caves of Belgium explored by M. Dupent, they presented but one perforation. The debates were very animated, and drew out many valuable remarks from the eminent ahthropologist, Dr. Paul Broca.

In the Geological section, papers were contributed by the Comte de Saporta, Mil. Dumnrtier, Beboux, and others, and in the debates Prof. Carl Voyt of Geneva took a prominent part. MM. Falsan and Chantre exhibited and described an elaborate map of the glacial phenomena of the middle basin of the Rhone, drawn on a large scale. They traced the glaciers of the Alps, and of the Jura, as far to the west as the Sâne, and as far to the south as Valence; and they proved that there were two epochs of glaciation, the one during which the area in question was covered by a great icc-sheet, conveying Alpine blocks over the Jura into the valley of the Sitone and middle basin of the Rhone, and the other during which the glaciers were isolated, and local moraines accumulated in the river valleys. These two periods correspond with those which have been noted in Great Britain and Ircland, by Prof. Ramsay, Hull, and others. The map presented a combination of artistic skill, with careful work in the field, which is very rarely met with.
In the evening three popular lectures were given to the public, one of which, by M. Janssen, on the Constitution of the Sun, was admirably illustrated.

The times of meeting of the sections differ from ours, the programme of the day being, first, a morning sitting from $\$ 32$, or 9 to in A.M.,-dejenter; and, an afternoon sitting from 3 to 5 P.M. - then dinner; and sometimes an cvening sitting commencing at eight, when there were no lectures gcing on. The sections were ${ } ;$ in number, and comprised Agriculture and Medicine, as wcll as those represented in the British Association. There were excursions down the Rhone, and to Geneva; a grand fot given by one of the merchants, and a magnificent entertainment given by the City of Lyons in the Town Hall.

In writing this short notice the extreme courtesy and consideration of the French Association to the strangers should not be omitted. Their hospitality to the enly" English guest present was too great to How from any personal motive, and cridently was intended as a mark of respect to the British Association.

\section{THE METEORULOGICAL CONGRESS AT}

\section{ITEN.VA}

IIE Meteorological Congress which met at Vienna during the past month worked very hard amid many difficulties, and we believe will have good results. The Congress sat from Sept. 2 to Sept. I6. The protocols arid appendices are in the press, and will appear officially in French and German; while Mr. R. H. Scott has undertaken an English translation, which will appear as soon as possible. The following is a list of the delegate: from the various countries:-Antonio Aguilar, Spain; H. Buys-Ballot, Netherlands ; Carl Bruhns, Germany; Alexander Buchan, Great Brita'n and Ireland; I. i). Campbell, China ; Ginv. Cantoni, Italy ; Aristide Coumbary, Turkey; v. Czelechowsky, Austria ; F. Doergens, Germany; Prof. Ebermayer, Bavaria; Fradesso d.r Silveira, Portugal ; M. Gloesener, Ibtlgium ; Julius Hann, Austria; Hofimeyer, Denmak ; Carl Jelinek, Austria; Josef Lorenz, Austria ; Heinrich Mohn, Norway ; Robert Mïller, Austrian-Hungary; Albert Myer, United States; Georg Neumayer, Germany; E. Plantamour, Sivitzerland ; Ernst Quetelet, Belgium ; R. Rubenson, Sweden ; Guicio Schenzî, Hungary ; Julius Schmidt, Grecce; H. Schoder, Germany; Rubert H. Scott, Great Britain and Ireland ; Carl Sohncke, Germany ; H. WVitd, Russia ; F. Winnecke, Germany; A. Zamara, Austria. The following is the programme of subjects discussed :-

I. Instruntents.-I. IWhat is the construction of the barometer most suitable for stations of the second order? Is the use of aneroids at such stations advisable? 2. What model of exposure of thermometers for the observation of air temperature is the best and most suitable for general adoption? 3. What is the best construction for maximum and minimum thermometers? 4. What instruments should be used for determining intensity of radiation, and in what way can the comparison of the results obtained be sccured? 5. What is the best apparatus for observing earth temperatures? At what depths ought they to be made, in order that the desired agrcement may be attained? 6. What instruments should be used for ascertaining the state of moisture of the atmosphere? Does the psychrometer suffice for this purpose? Can the hair hygrometer be made applicable, and with what limitations? 7. In what way can an agreement in the signs for the directions of the wind be attained? Is the deduction of the mean direction of the wind according to Lambert's formula desirable? Is it desirable or not to include very light winds (force o) in constructing wind roses for the direction of the wind? 8. What scale is to be used for the force of wind where it has to be estimated without the aid of an instrument? 9 . Is the 